eCommons@AKU

April 2017

\title{
Raising taxes key to accelerate tobacco control in South Asia
}

Prabhat Jha

University of Toronto, Canada

Javaid Khan

Aga Khan University, javaid.khan@aku.edu

Sujata Mishra

Prakash Gupta

Healis-Sekhsaria Institute for Public Health, Mumbai, India

Follow this and additional works at: https://ecommons.aku.edu/ pakistan_fhs_mc_med_pulm_critcare

Part of the Pulmonology Commons

\section{Recommended Citation}

Jha, P., Khan, J., Mishra, S., Gupta, P. (2017). Raising taxes key to accelerate tobacco control in South Asia. BMJ, 357(j1176), 1-4. Available at: https://ecommons.aku.edu/pakistan_fhs_mc_med_pulm_critcare/57 


\title{
Raising taxes key to accelerate tobacco control in South Asia
}

\author{
South Asian countries must prioritise higher tobacco taxation and other control measures \\ to raise the low levels of tobacco cessation and thus avoid millions of premature deaths, \\ say Prabhat Jha and colleagues
}

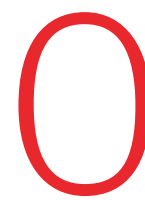

n current smoking patterns, tobacco will kill about 1 billion people worldwide this century, ${ }^{12}$ including substantial numbers in the South Asian countries. All South Asian countries have signed the Framework Convention on Tobacco Control and have committed to the United Nations (UN) sustainable development goals (SDG), including to reduce premature mortality from non-communicable diseases by one third by $2030 .^{3}$ Achieving this goal will depend on effective implementation of the tobacco control measures set out in the framework convention. ${ }^{4}$ The most important of these is large increases in the excise tax on tobacco products.

Here, we mostly focus on initiatives to control smoking because smoked tobacco causes more systemic diseases and has higher overall risks for the user than other forms of tobacco use. We also briefly review the status of smokeless tobacco.

\section{Methods}

We examined nationally representative surveys of tobacco use in India, Bangladesh and $\mathrm{Nepal}^{5-8}$ and relied upon WHO reports on surveys done in the South Asian countries. ${ }^{4}$ To estimate the number of tobacco users, we applied the prevalence of smokers and smokeless tobacco users at ages 15+ in these surveys to the UN 2010 population estimates. ${ }^{9}$ To estimate the number of future smokers under 35 years, we applied the smoking prevalence at ages 25-34 to the UN 2010 population under age 25 , and added

\section{KEY MESSAGES}

South Asia has large and growing numbers of tobacco users and very low rates of cessation

Effective implementation of the Framework Convention on Tobacco Control, in particular its tax provisions, could reduce tobacco consumption by at least one third and save about 35-45 million lives

Non-price measures and registration and better regulation of bidi and chewing tobacco sectors are essential to complement taxation of cigarettes current smokers at ages 25-34. We applied the Indian ratios of smoking prevalence at ages 25-34 for countries where prevalence was not reported by age. ${ }^{5}$ To estimate the number of deaths from smoking, we assumed that half of the $<35$ smokers would be killed from smoking, as they are likely to face the full risks that have been recently documented among continuing smokers who start early in adult life. ${ }^{10-12}$ However, if they stopped by age 40 , the $<35$ smokers would gain back nearly all of the life lost from continued smoking. ${ }^{10-13}$ For current smokers above age 35 who quit, we applied age-specific reductions in risk for stopping at various ages, based on recent reviews. ${ }^{213}$

\section{Current patterns of smoking}

Nearly $30 \%$ of males and only $4 \%$ of females aged 15 or older in South Asian countries smoke (table 1), with notable variation between countries. In 2010, most of the roughly 170 million adult smokers in South Asia were male and most lived in India. A substantial number of people in India smoke cigarettes and bidis (a small, locally grown and mostly unregulated form of smoked tobacco). In Bangladesh, Nepal, and Pakistan, most smoked tobacco is in the form of cigarettes. Smoking generally starts at a later age (about 25 years, although the mean age of onset in Nepal is about $18^{8}$ ) and with fewer daily cigarettes or bidis (weighted mean daily consumption of about 9, 8 and 7 in Nepal, India, and Bangladesh, respectively $)^{5-8}$ than in high income countries, where most smokers start before age 20 and the mean number of cigarettes smoked a day is over $15 . .^{15}$ In India and Bangladesh, cigarettes have gradually displaced bidis, ${ }^{716}$ particularly among younger and illiterate males. ${ }^{16}$

Importantly, smoking cessation rates are quite low in South Asia. Cessation is reliably measured by the prevalence of former tobacco use as a proportion of the adult population at ages 45-59, when adults are most likely to want to consider quitting. Among men, the former smoking prevalence in India and Nepal is below 5\%5816 but higher in Bangaldesh. ${ }^{17}$ In contrast, in high income countries such as the United States, the prevalence of former smoking is more than the current smoking prevalence by age $50 .{ }^{10}$ Much of the cessation in South Asia, however, is because disease has developed and not to avoid the development of disease.

\section{Consequences of smoking and benefits of cessation}

Despite the relatively late age of starting smoking and the low number of cigarettes or bidis smoked a day, the hazards of smoking are considerable. In India, the nationally representative Million Death Study documented that smoking caused about a quarter of all deaths among men aged 30-69 in $2010 .{ }^{18}$ Similar proportions of deaths from smoking were observed in Bangladeshi men. ${ }^{19}$ Higher daily amounts of smoking are associated with increased risks of death compared with non-smokers (fig 1). Indeed, the loss of life among Indian male cigarette smokers $^{18}$ is as extreme as now observed in prolonged smokers in high-income countries. ${ }^{10-12}$ The proportion of deaths among adults caused by tobacco will rise in most South Asian countries because of increased rates of smoking and population growth. ${ }^{1}$

Evidence from high-income countries ${ }^{1210-12}$ and emerging evidence from China ${ }^{20}$ reveals that, in contrast to the slow hazards of smoking, cessation is effective quickly. Those who stop smoking before age 40 avoid about $90 \%$ of the excess risk of continued smoking, and will regain nine years of life. Those who stop by the age of 50 and 60 years regain about six and four years of life, respectively.

\section{Insufficient use of higher taxes for tobacco control}

Comprehensive tobacco-control programmes include both price and non-price interventions and have been shown to substantially reduce tobacco use..$^{13}$ However, South Asian countries show only modest levels of coverage of interventions to raise cessation. ${ }^{4}$ Increases in tobacco tax are the single most effective intervention. ${ }^{12413}$ The International Agency for Research on Cancer reviewed over 100 econometric studies and concluded that a 50\% increase in inflation adjusted prices reduces tobacco consumption by about $20 \% .^{21}$ Studies from many countries have verified the inverse relationship between price and consumption. ${ }^{22-26}$ 


\begin{tabular}{|c|c|c|c|c|c|c|c|c|c|c|c|}
\hline \multirow[b]{2}{*}{ Country } & \multirow{2}{*}{$\begin{array}{l}\text { Total population } \\
\text { aged } \geq 15 \text { years } \\
\text { (millions) }\end{array}$} & \multicolumn{3}{|c|}{$\begin{array}{l}\text { Reported prevalence of } \\
\text { smokers aged } \geq 15(\%)^{*}\end{array}$} & \multicolumn{3}{|c|}{$\begin{array}{l}\text { Estimated No of smokers } \\
\text { aged } \geq 15 \text { in } 2010 \text { (millions) }\end{array}$} & \multicolumn{3}{|c|}{$\begin{array}{l}\text { Estimated No of future smokers } \\
\text { among people aged } 0-34 \text { years } \\
\text { (millions) }\end{array}$} & \multirow[t]{2}{*}{$\begin{array}{l}\text { No of deaths in } \\
\text { current and future } \\
\text { smokers (millions) }\end{array}$} \\
\hline & & Males & Females & Total & Males & Females & Total & Males & Females & Total & \\
\hline India & 851 & 24 & 3 & 14 & 107 & 13 & 120 & 96 & 5 & 101 & 51 \\
\hline Bangladesh & 109 & 37 & 1 & 19 & 19 & 0.5 & 20 & 18 & 0.2 & 19 & 9 \\
\hline Pakistan & 103 & 36 & 7 & 22 & 20 & 4 & 24 & 8 & 4 & 12 & 6 \\
\hline Others $^{\dagger}$ & 47 & 26 & 4 & 15 & 6 & 1 & 7 & 6 & 2 & 8 & 4 \\
\hline All South Asia & 1110 & 29 & 4 & 16 & 152 & 19 & $171^{\ddagger}$ & 128 & 11 & $140^{\S}$ & 70 \\
\hline
\end{tabular}

*Smoking prevalence is from GATS 2009 for India ${ }^{5}$; from ITC Bangladesh Enumeration Phase 2-2012 for Bangladesh ${ }^{7}$; from WHO for Pakistan, Maldives and Sri Lanka ${ }^{4}$; from the World Tobacco Atlas for Afghanistan and Bhutan ${ }^{14}$; and from STEPS Survey for Nepal ${ }^{8}$

tOther countries include Afghanistan, Bhutan, Nepal, Maldives, and Sri Lanka.

$\neq$ Of the 171 million smokers aged $\geq 15$, about 100 million are aged 35 or older.

§Of the 140 million smokers aged < 35 years, 33 million are current smokers aged 25-34 years and 107 million are future smokers below age 25 years.

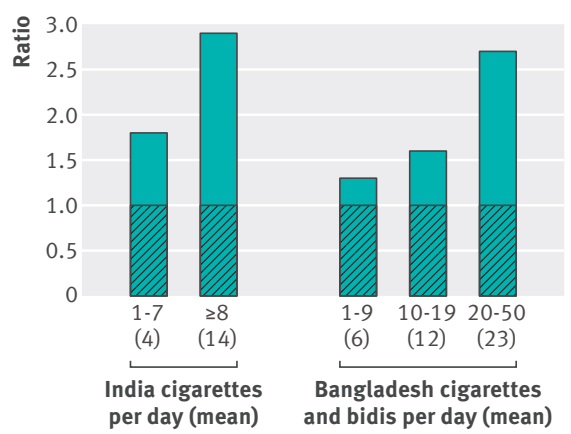

Figure $1 \mid$ Risk of death by amount and type, men aged 30-69 years in India and Bangladesh. Risk ratios are for smokers as compared with non-smokers, adjusted for age, education, chewing tobacco and, in India, for alcohol use. ${ }^{1819}$

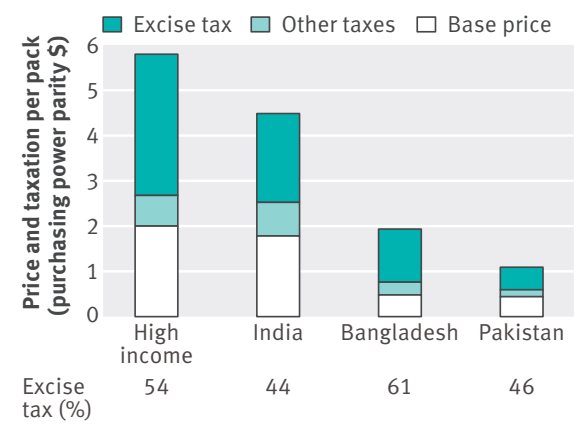

Fig 2 | Contributions of specific excise taxes on tobacco and other taxes to the total cost per pack of the most sold brand of cigarettes in 48 high income countries, India, Bangladesh, and Pakistan. Prices are expressed in dollars adjusted for purchasing power parity (PPP) 4

France, for example, tripled the price of cigarettes over 12 years and consumption fell from about six cigarettes per adult per day to three. ${ }^{1}$ Thus, doubling inflation adjusted prices would be expected to reduce consumption by at least one third. About half of the reduced consumption is because people quit or do not start smoking and about half because people smoke fewer cigarettes. Price effects are greatest in the young and among poor people. ${ }^{1321}$

In South Asian countries, the cost of cigarettes, bidis, and chewing tobacco is low. ${ }^{427}$ In Canada, the UK and several other high- income countries, about $60 \%$ of the retail price of the most-sold brand of cigarette is a specific excise tax, and WHO recommends that the excise tobacco tax should form $75 \%$ of the final retail price. ${ }^{4}$ Low levels of excise tax are the main reason for the price differences between high-income and South Asian countries (fig 2).

Taxation strategies need to consider high levels of taxation as well as their tax structure to effectively raise tobacco prices. The two major types of tobacco tax are ad valorem taxes (based on the price set by the manufacturer) and specific excise taxes (usually set at a fixed rate based on weight or quantity rather than the value of the product). Manufacturers can manipulate ad valorem taxes by altering base prices but have less influence on excise taxes.Excise taxes are simpler to administer and result in more predictable reduction in smoking and increase in government revenue. ${ }^{21}$

The main reason for limited tobacco control in South Asia, in particular the limited use of large tax increases, is opposition from the tobacco industry because of the considerable profits from tobacco (roughly $\$ 10000$ [€8000; €9000] profit per tobacco death worldwide ${ }^{1}$ ). Annual increases in tobacco tax have mostly been below the rate of inflation and income growth, so cigarettes remain affordable. In fact, the stock price of the cigarette industry has risen after ineffective budgets such as the February 2017 budget in India, which increased cigarette taxes by well below the rate of income growth. ${ }^{2829}$ Variation in the tax rates, usually based on the different lengths of cigarettes, leads to price differences and enables smokers to change to cheaper brands or shorter cigarettes. ${ }^{27}$ Furthermore, the sale of single cigarettes is common in South Asia, which reduces the effectiveness of tax increases.

The most effective non-price interventions include a complete ban on tobacco advertising and promotion, use of large pictorial warnings or use of plain packaging on tobacco products, and a complete ban on smoking in public places. ${ }^{12413}$
Implementation of these interventions is variable, but slowly increasing in the region. ${ }^{4}$ The use of plain packaging or prominent pictorial warning labels is particularly relevant given the high levels of illiteracy among tobacco users in the region. Nationwide epidemiological studies on the effects of tobacco control have been influential in shaping local debates and public understanding of the dangers of tobacco use. ${ }^{21318}$ Such studies can also monitor the prevalence of former tobacco use at ages 45-59, which is a reliable measure of the effectiveness of tobacco control policies. Smoking cessation programmes are uncommon in the region. Most people who quit do so without physician advice, nicotine replacement therapy, or electronic cigarettes. Finally, South Asian countries spend little on tobacco control, despite the absolute costs of tobacco control programmes being very low.

\section{Accelerating tobacco control}

Given the substantial premature mortality from tobacco use, and the fact that reduction in the uptake of smoking by young people will mostly reduce deaths after $2050^{12}$ achieving the sustainable development goal $^{3}$ will require a substantial increase in cessation. A report by the Asian Development Bank on five Asian countries, including India, concluded that increasing the price of cigarettes by $50 \%$ through excise tax increases of $70-122 \%$ would reduce the number of current and future smokers by nearly 67 million and reduce tobacco deaths by over 27 million in the five countries. Moreover, about \$24bn additional revenue would be generated annually. ${ }^{30}$ The Philippines has set an example and increased tobacco taxes substantially despite opposition from the tobacco industry. By 2017, cigarettes are subject to a single unitary excise tax of $\$ 0.70$, which will further increase by $4 \%$ each year. ${ }^{31}$

Higher cigarette taxes do not necessarily encourage smokers to change to bidis, as the two markets are separate. ${ }^{27} \mathrm{An}$ increase in 
Table 2 Prevalence of current smokeless tobacco consumption in South Asia among people aged $\geq 15$

\begin{tabular}{|c|c|c|c|c|c|c|}
\hline \multirow[b]{2}{*}{ Country } & \multicolumn{3}{|c|}{ Smokeless tobacco prevalence* $(\%)$} & \multicolumn{3}{|c|}{ Current smokeless users (millions) in 2010} \\
\hline & Total & Males & Females & Males & Females & Total \\
\hline India & 33 & 18 & 26 & 145 & 74 & 219 \\
\hline Bangladesh & 19 & 25 & 22 & 10 & 13 & 23 \\
\hline Pakistan & 22 & 5 & 14 & 12 & 3 & 15 \\
\hline Others $^{\dagger}$ & 15 & 10 & 13 & 4 & 2 & 6 \\
\hline All South Asia & 20 & 11 & 16 & 171 & 92 & 263 \\
\hline
\end{tabular}

*Smoking prevalence is from GATS 2009 for Indias'; from ITC Bangladesh Enumeration Phase 2-2012 for Bangladesh'; from WHO for Pakistan, Maldives and Sri Lanka $a^{4}$; from the World Tobacco Atlas for Afghanistan and Bhutan ${ }^{14}$ and from STEPS Survey for Nepal; ; tOther countries include Afghanistan, Bhutan, Nepal, Maldives, and Sri Lanka.

smuggling and tax avoidance has been raised as an objection to higher taxes. However, even with moderate levels of smuggling or tax avoidance, higher taxes reduce tobacco use and raise revenue. ${ }^{1321}$ In fact, excise taxation can raise tax compliance and should help counter smuggling. ${ }^{421}$

\section{Reduction in mortality from a tripling of excise taxes}

The benefits of reduced consumption are different for different age and smoking groups. We looked at current and future smokers aged under 35 (total of 140 million, of whom about 33 million are current smokers aged 25-34 and 107 million under 25 who have not yet started) and the 100 million current smokers over 35 (out of a total of 171 million smokers at ages 15 or more; table 1 ). Without large increases in the currently low levels of cessation, at least half of the cohort of 140 million young and future smokers would die because of smoking. At least half of these 70 million deaths would occur before age 70 , losing many years of good life. (Smokers not killed by their smoking lose zero years of life, but those who are killed by smoking lose on average 20 or more years compared with otherwise similar non-smokers). Not starting smoking or complete cessation before age 40 would avoid nearly all of these deaths. A tripling of the excise taxes, designed in particular to decrease downward substitution from more expensive to cheaper brands, would likely reduce smoking in South Asia by at least one third. ${ }^{2421} \mathrm{~A}$ one third reduction in tobacco use would reduce the cohort of 140 million younger or future smokers under 35 years by about 50 million smokers, avoiding at least 25 million deaths. The benefits of a one third reduction in the 100 million current smokers over 35 years depend on their age of cessation. Conservatively, such a reduction might avoid about 10-20 million deaths, most of which would be before $2050 .^{12}$

\section{Consequences and control of smokeless \\ tobacco use}

Over 260 million adults chewed tobacco in South Asia in 2010, including 92 million women (table 2). Chewed tobacco products can be made industrially (eg, gutka in India or naswar in Afghanistan), by the seller (eg, betel quid), or even prepared by the user (eg, khaini or tobacco and slaked lime mixtures). Most chewed tobacco products are unregulated and can contain high levels of toxic and carcinogenic substances. ${ }^{32}$ Chewing cessation is also uncommon: below $5 \%$ at ages 45-59 in both India and Bangladesh. ${ }^{5-7}$ Trend results have been inconsistent, showing both increases and decreases in chewing. ${ }^{733}$

The individual risk of death from chewed tobacco is lower than from smoked tobacco, but it is nonetheless a major risk to health in the region. ${ }^{34}$ In particular, South Asia has among the highest rates of oral cancer in the world, and the incidence of oral cancer has risen sharply in some urban areas. ${ }^{35}$ Importantly the risk of non-fatal oral cancers among quid users is higher in women than men, even though women chew fewer quid per day. This might reflect peculiarities in use-for example, chewing tobacco is common among older women and those of a lower socioeconomic status, and women tend to keep the tobacco in their mouths for longer than men. ${ }^{36}$

Unlike the few registered cigarette manufacturers, most of which are part of multinational companies, the thousands of small bidi and smokeless tobacco businesses in South Asia are often controlled by non-transparent organisations that are not registered, regulated, or taxed. ${ }^{37}$ Practical steps to regulate the bidi and smokeless tobacco industry involve registration and eliminating the tax differential between machine and handmade bidis. ${ }^{27}$ Until the bidi and smokeless tobacco sectors are better regulated, it will be difficult to impose large excise taxes such as for cigarettes. In the meantime, the use of prominent pictorial warning labels or plain packaging and restrictions on local advertising are likely to be the most effective methods of control. ${ }^{13}$

We thank Leslie Newcombe for editorial help. Contributors and sources: This article is based on ongoing epidemiological and economic research conducted by the authors. PJ, JK, PCG have expertise in epidemiology, and PJ and SM have expertise in economics. All authors have experience in evidence based tobacco control. PJ is the guarantor.

Competing interests: We have read and understood BM] policy on declaration of interests and declare external funding from the Fogarty International Center of the US National Institutes of Health (No. R01 TW05991-01), International Development Research Centre (No. 102172), University of Toronto (CGHR support). PJ is supported by the Canada research chair programme.

Provenance and peer review: Commissioned; externally peer reviewed.

Prabhat Jha, professor $^{1}$

Javaid Khan, professor ${ }^{2}$

Sujata Mishra, professor ${ }^{1}$

Prakash Gupta, professor ${ }^{3}$

${ }^{1}$ Centre for Global Health Research, St Michael's Hospital and Dalla Lana School of Public Health, University of Toronto, Toronto, Canada

${ }^{2}$ Aga Khan University, Karachi, Pakistan

${ }^{3}$ Healis-Sekhsaria Institute for Public Health,

Mumbai, India

Correspondence to: PJha prabhat.jha@utoronto.ca

Jha P, Peto R. Global effects of smoking, of quitting, and of taxing tobacco. N Engl/ Med 2014;370:60-8. doi:10.1056/NEJMra1308383.

Jha P. Avoidable global cancer deaths and total deaths from smoking. Nat Rev Cancer 2009;9:655-64. doi:10.1038/nrc2703.

Norheim OF, Jha P, Admasu K, et al. Avoiding 40\% of the premature deaths in each country, 2010-30: review of national mortality trends to help quantify the UN sustainable development goal for health. Lancet 2015;385:239-52. doi:10.1016/

S0140-6736(14)61591-9.

World Health Organization. WHO report on the global tobacco epidemic, 2015: raising taxes on tobacco. WHO, 2015. http://www.who.int/tobacco/ global_report/2015/report/en/

5 International Institute for Population Sciences. Global adult tobacco survey: India report. Mumbai, India. Indian Ministry of Health and Family Welfare, 2010.

6 Ministry of Health and Family Welfare.Global adult tobacco survey: Bangladesh report. World Health Organization, 2009.

Nargis N, Thompson ME, Fong GT, et al. Prevalence and patterns of tobacco use in Bangladesh from 2009 to 2012: evidence from International Tobacco Control (ITC) study. PLoS One 2015:10:e0141135. doi:10.1371/ journal.pone.0141135.

8 Aryal KK, Neupane S, Mehata S, et al. Non communicable diseases risk factors: STEPS Survey Nepal 2013. Nepal Health Research Council, 2014. http://www.searo.who.int/nepal/mediacentre/ non_communicable_diseases_risk_factors_steps survey_nepal_2013.pdf.

9 UN Department of Economic and Social Affairs. World population prospects: the 2015 revision. 2015. https:// esa.un.org/unpd/wpp/

10 Jha P, Ramasundarahettige C, Landsman V, et al. 21st-century hazards of smoking and benefits of cessation in the United States. N Engl I Med 2013:368:341-50. doi:10.1056/NEJMsa1211128.

1 Pirie K, Peto R, Reeves GK, Green J, Beral V. Million Women Study Collaborators. The 21st century hazards of smoking and benefits of stopping: a prospective study of one million women in the UK. Lancet 2013;381:133-41. doi:10.1016/ S0140-6736(12)61720-6.

12 Doll R, Peto R, Boreham J, Sutherland I. Mortality in relation to smoking: 50 years' observations on male British doctors. BM/2004:328:1519-33. doi:10.1136/ bmj.38142.554479.AE.

13 Jha P, MacLennan M, Chaloupka FJ, et al. Global hazards of tobacco and the benefits of smoking cessation and tobacco taxes. In: Gelband H, Jha P, Sankaranarayanan R, Horton S, eds. Cancer: disease control priorities. Vol 3, 3rd ed. World Bank, 2015:175-93. doi:10.1596/978-1-4648-0349-9_ch10

14 Eriksen M, Mackay J, Schluger N, Gomeshtapeh FI, Drope J. The tobacco atlas.American Cancer Society, 2015.

15 Ng M, Freeman MK, Fleming TD, et al. Smoking prevalence and cigarette consumption in 187 countries, 1980-2012. JAMA 2014;311:183-92. doi:10.1001/jama.2013.284692 
16 Mishra S, Joseph RA, Gupta PC, et al. Trends in bidi and cigarette smoking in India from 1998 to 2015 by age, gender and education. BMJ Glob Health 2016;1:e000005. doi:10.1136/bmjgh-2015000005

17 Abdullah AS, Driezen P, Quah ACK, Nargis N, Fong GT. Predictors of smoking cessation behavior among Bangladeshi adults: findings from ITC Bangladesh survey. Tob Induc Dis 2015;13:23. doi:10.1186/ s12971-015-0050-y.

18 Jha P, Jacob B, Gajalakshmi V, et al. RGI-CGHR Investigators. A nationally representative case-control study of smoking and death in India. N Engl J Med 2008;358:1137-47. doi:10.1056/NEJMsa0707719.

19 Alam DS, Jha P, Ramasundarahettige C, et al. Smoking-attributable mortality in Bangladesh: proportional mortality study. Bull World Health Organ 2013;91:757-64. doi:10.2471/BLT.13.120196.

20 Chen Z, Peto R, Zhou M, et al. China Kadoorie Biobank (CKB) collaborative group. Contrasting male and female trends in tobacco-attributed mortality in China: evidence from successive nationwide prospective cohort studies. Lancet 2015;386:1447-56 doi:10.1016/S0140-6736(15)00340-2.

21 International Agency for Research on Cancer. Effectiveness of tax and price policies for tobacco control: IARC handbook of cancer prevention. IARC, 2011.

22 Guindon GE, Nandi A, Chaloupka FJ, Jha P. Socioeconomic differences in the impact of smoking tobacco and alcohol prices on smoking in India. National Bureau of Economic Research Working Paper No 17580. 2011. doi:10.3386/w17580
23 Mushtaq N, Mushtaq S, Beebe LA. Economics of tobacco control in Pakistan: estimating elasticities of cigarette demand. Tob Control 2011;20:431-5. doi:10.1136/tc.2010.040048

24 Arunatilake N, Opatha M. The economics of tobacco in Sri Lanka. Health, Nutrition and Population (HNP) discussion paper. Economics of tobacco control paper; no. 12. World Bank, 2003.

25 Karki YB, Pande BR, Pant KD. A study on the economic of tobacco in Nepal. Health, Nutrition and Population (HNP) discussion paper. Economics of tobacco control paper; no. 13. World Bank, 2003.

26 Nargis N, Ruthbah UH, Hussain AKMG, Fong GT, Huq I, Ashiquzzaman SM. The price sensitivity of cigarette consumption in Bangladesh: evidence from the International Tobacco Control (ITC) Bangladesh Wave 1 (2009) and Wave 2 (2010) Surveys. Tob Control 2014;23(Suppl 1):i39-47. doi:10.1136/tobaccocontrol-2012-050835.

27 Jha P, Guindon E, Joseph RA, et al. A rational taxation system of bidis and cigarettes to reduce smoking deaths in India. Econ Polit Wkly 2011;46:44-51.

28 ITC, other cigarette stocks rally up to $4 \%$ as govt hikes excise duty marginally. Economic Times 2017 Feb 1. http://economictimes.indiatimes.com/markets/ stocks/news/articleshow/56912705.cms

29 Jha P, Gupta PC, Guindon E, Mishra S. Analyses of 2017 Union Budget tobacco tax increase. $2017 \mathrm{http} / / / \mathrm{www}$. cghr.org/wordpress/wp-content/uploads/Analyses-of2017-Union-Budget-Tobacco-Tax-Increase.pdf

30 Jha P, Joseph RA, Li D, et al. Tobacco taxes: a win-win measure for fiscal space and health.Asian Development Bank, 2012.
31 Kaiser K, Bredenkamp C, Iglesias R. Sin tax reform in the Philippines: transforming public finance, health, and governance for more inclusive development. World Bank, 2016doi:10.1596/ 978-1-4648-0806-7

32 Bhisey RA. Chemistry and toxicology of smokeless tobacco. Indian J Cancer 2012;49:364-72. doi:10.4103/0019-509X107735.

33 Sinha DN, Rizwan SA, Aryal KK, Karki KB, Zaman MM Gupta PC. Trends of smokeless tobacco use among adults (aged 15-49 years) in Bangladesh, India and Nepal. Asian Pac) Cancer Prev 2015;16:6561-8. doi:10.7314/APICP.2015.16.15.6561.

34 Gupta PC, Ray CS, Sinha DN, Singh PK. Smokeless tobacco: a major public health problem in the SEA region: a review. Indian J Public Health 2011;55:199209. doi:10.4103/0019-557X.89948.

35 Gupta PC, Ray CS, Murti PR, Sinha DN. Rising incidence of oral cancer in Ahmedabad city. Indian I Cancer 2014;51(Suppl 1):S67-72.

36 Singhal S, Gupta PC, Dikshit R, Jha P. Increased risk of coronary heart disease in female smokers. Lancet 2012;379:802, author reply 803. doi:10.1016/ S0140-6736(12)60345-6.

37 Nandi A, Ashok A, Guindon GE, Chaloupka FJ, Jha P. Estimates of the economic contributions of the bidi manufacturing industry in India. Tob Control 2015;24:369-75. doi:10.1136 tobaccocontrol-2013-051404

Cite this as: BMJ 2017;357:j1176 http://dx.doi.org/10.1136/bmj.j1176 